\section{GENERAL DISCUSSION}

Both increased incentive and increased deprivation were associated with higher response rates in the punishment phase, although it was unclear if the differences between prepunishment and punishment rates were affected similarly. Suppression in the punishment and conditioned suppression procedures appears to be affected similarly by differences in food deprivation but not by differences in sucrose concentration. The finding that increased incentive $h$ as little effect on conditioned suppression, at least within the $8 \%-32 \%$ range, but a large effect on resistance to punishment within the same range and the inconsistencies in the literature reviewed in the introduction raise problems for Estes's theory (1969), which explains the amount of suppression in conditioned suppression and punishment situations as being determined by a conflict between appetitive and aversive motivation.

These data bear on another aspect of conflict theory. Since punishment was scheduled on a FR schedule, it might be supposed on a variety of grounds (Brody, 1968; Bower \& Miller, 1960) that response rates would be highest at the beginning of the ratio and decline as the ratio ran out. Despite extensive exposure to the FR 200 schedule in the present studies, however, there was no evidence in the cumulative records of differential response rate as a function of position in the ratio, except for short postshock pauses. These data are in accord with the results of other studies which indicate that no negative acceleration occurs between shocks in FR punishment situations when the manipulandum is not part of the shock circuit (Azrin, Holz, \& Hake, 1963; Hendry \& Van Toller, 1964).

\section{REFERENCES}

AYRES, J. J. B. Differentially conditioned suppression as a function of shock intensity and incentive. Journal of Comparative \& Physiological Psychology. $1968,66,208-210$.

AYRES, J. J. B., \& QUINSEY, V. L. A conditioned suppression test of the suppression theory of punishment. Paper presented at Eastern Psychological Association, Philadelphia, 1969 .

AZRIN, N. H., HOLZ, W. C., \& HAKE, D. F. Fixed-ratio punishment. Journal of the Experimental Analysis of Behavior, 1963 , 6, 141-148.

BOWER, G. H., \& MILLER, N. E. Effects of amount of reward on strength of approach in an approach-avoidance conflict. Journal of Comparative \& Physiological Psychology, 1960, 53, 59-62.

BRODY, J. F. Response patteming under fixed-ratio punishment. Psychological Reports, 1968, 23, 575-587.

ESTES, W. K. Outline of a theory of punishment. In B. A. Campbell and R. M. Church (Eds.), Punishment and aversive behavior. New York: Appleton-CenturyCrofts, 1969. Pp. 57-82.
FER RARO, D. P. Persistence to continuous punishment as a function of amount of reinforcement. Psychonomic Science, $1966,6,109-110$.

GUTTMAN, N. Operant conditioning. extinction, and periodic reinforcement in relation to concentration of sucrose used as reinforcing agent. Journal of Experimental Psychology, 1953, 46 , 213-224.

HENDRY, D. P., \& VAN TOLLER, C Fixed-ratio punishment with continuous reinforcement. Journal of the Experimental Analysis of Behavior, 1964, 7. 293-300.
KURTZ, K. H. Food deprivation and effort expended for food. Leaming \& Motivation, 1970, 1, 281-296.

LEAF, R. C., \& MULLEK, S. A. Elfects of shock intensity, deprivation, and morphine in a simple approach-avoidance conflict situation. Psychological Reports, $1965,17,819-823$.

VOGEL, J. R., \& SPEAR, N. E. Interaction of reward magnitude and conditioned fear on the consummatory response. Psychonomic Science, 1966, 5, 263-264.

\title{
The effects of chlorpromazine on self-punitive behavior*
}

\author{
R. CHRIS MARTIN, B. L. DEEMER, and NANCY MCARDLE \\ University of Missouri, Kansas City, Mo. 64110 \\ SUSAN STOKELY \\ Institute for Behavior Research, Silver Spring, Md. 20910 \\ and \\ SOLOMON STEINER \\ City College of New York, New York, N.Y. 10031
}

After usual treatment conditions were instated to produce the self-punitive behavior phenomenon, different dose levels of chlorpromazine (or appropriate amounts of saline) were administered to different groups of rats. The overall effects of the drug were suppression of performance. The most interesting result occurred at the low dose level, in that only the punished group was affected by the drug. These findings support the Mowrer-Brown theoretical explanation of self-punitive behavior. In addition, these findings indicate that the self-punitive paradigm has promise as a drug-screen technique.

One possible consequence of punishment is suppression of the pun ished response; Whenever punishment facilitates the response, however, this particular kind of maladaptive behavior is called self-punitive, or vicious circle, behavior (Brown, Martin, \& Morrow, 1964). During the past few years, most of the necessary and sufficient conditions for the production of self-punitive behavior have been isolated (see review by Brown, 1969). At the same time, the Mowrer-Brown theoretical explanation, which emphasizes motivational and reinforcement aspects, has been strongly supported. Within the Mowrer-Brown explanation, it is presumed that there are at least three sources of contribution to the motivational level operating in the self-punitive situation: (1) the punishment itself, (2) conditioned fear, and (3) residual emotionality.

* This research was supported in part by Grant 2167-2232 (UMKC) from Dr. F. Otto Haas and Grant 2189-2100 (UMKC). The authors appreciate the critical reading by Drs. C. Sheridan and D. Justesen.
Based upon the reasoning that a significant reduction in motivation should lower response strength, several attempts have been made to stop self-punitive behavior by reducing the level of motivation. Martin (1968) and Ervey (1969) reduced residual emotionality by removing the $S$ from the test situation for a time and thus decreasing self-punitive behavior. Since major tranquilizers presumably lower motivation, different dose levels of chlorpromazine were used in the present study in an attempt to stop self-punitive behavior. Miller, Murphy, \& Misky (1957) have shown that fear-reducing properties of chlorpromazine were not attributable to motor and/or sedative effects of the drug at dose levels near $1.2 \mathrm{mg} / \mathrm{kg}$.

\section{SUBJECTS}

The Ss were 108 naive female rats of the CFE strain obtained from Carworth Labs. The Ss were received as weanlings and were handled daily for 1 week. When Ss weighed approximately $90 \mathrm{~g}$, they were housed in individual cages with food and water available ad lib. When used in the experiment, $S$ s weighed 

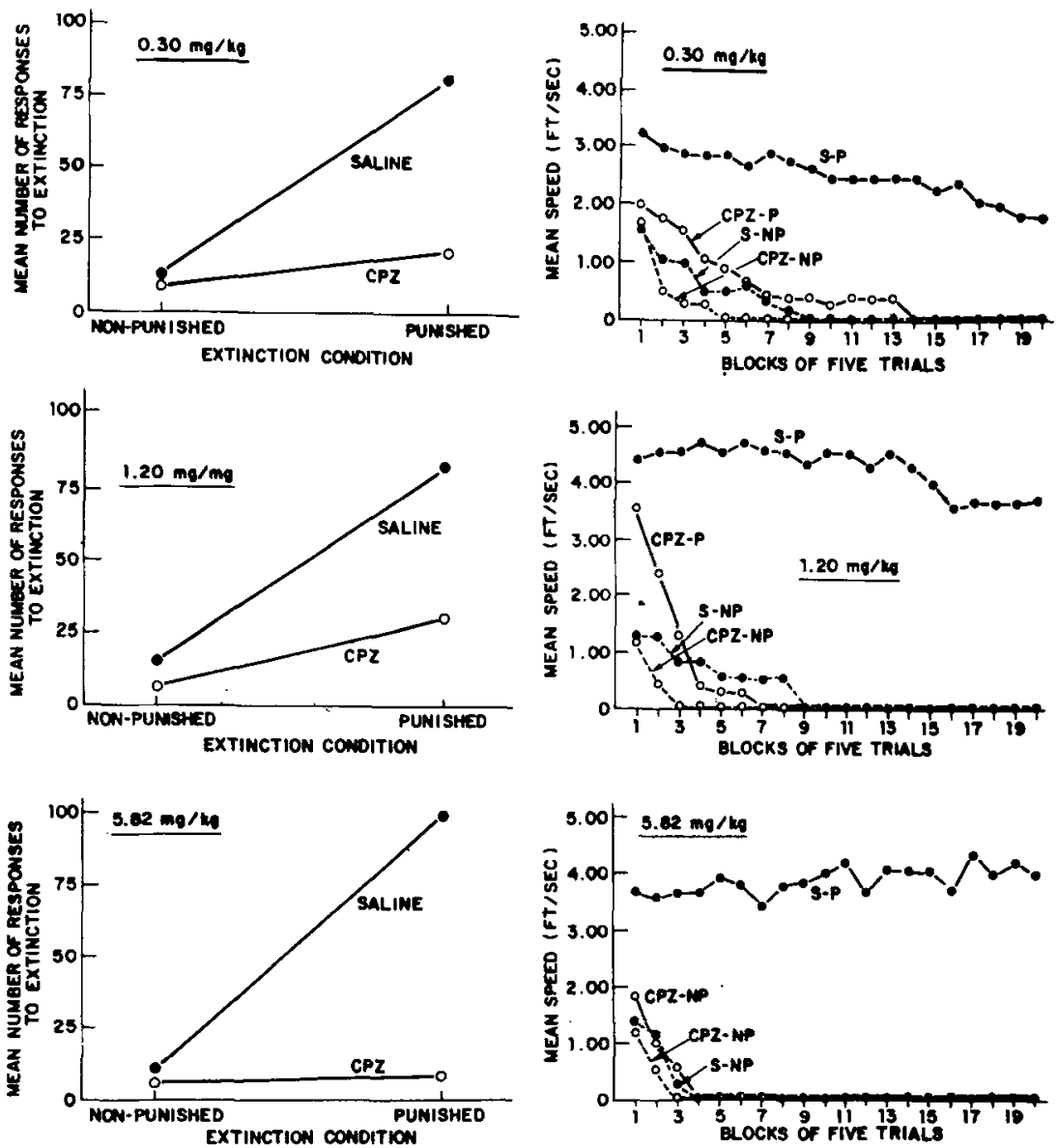

Fig. 1. Resistance to extinction, as measured by number of responses and alley speed, of all groups of punished and nonpunished Ss at each dose level.

approximately $135 \mathrm{~g}$ and were deprived of food for $24 \mathrm{~h}$ prior to the experimental session.

\section{APPARATUS}

The main apparatus was a striaight runway and has been described in detail elsewhere (Martin, 1969). The white startbox $(12 \times 12 \times 8$ in. $)$ and alley ( $72 \times 12 \times, 8$ in.) had a grid floor through which shock could be administered. The black goalbox (12 $\times 12 \times 12$ in.) had a wooden floor. Guillotine doors separated the compartments. Hunter Klockounters and appropriately placed photocells permitted the measurement of starting and alley times.

\section{PROCEDURE}

The study was run in three phases, Each time a dose level of drug was tested, the appropriate saline-injected control groups were also run.

\section{Acquisition}

Before any treatment condition was imposed, $\mathbf{S}$ was given 33 shock-escape $(1.0 \mathrm{~mA})$ trials with a 30 -sec intertrial interval. Before the 34 th acquisition trial, $\mathbf{S}$ was given an interperitoneal injection of chlorpromazine $(.3,1.2$, or $5.8 \mathrm{mg} / \mathrm{kg}$ ) or an equivalent volume of saline.

\section{Extinction}

After the 35th shock-escape trial, S received either punished extinction conditions or nonpunished extinction trials. During nonpunished extinction, shock was no longer present in any portion of the apparatus. In the punishment condition, $\mathbf{S}$ encountered shock in the $18 \mathrm{in}$. of the alley immediately in front of the startbox. Up to 100 extinction trials were administered unless $S$ met the criterion for extinction (failure to enter the goalbox within $60 \mathrm{sec}$ ).

A control procedure was instituted to guard against the possibility that the drug rendered $S$ unable to perform the response, i.e., groups of Ss were run which were given 100 more shock-escape trials after the administration of the drug.

\section{RESULTS}

Extinction performance in number of responses to extinction and in feet per second (alley speed) during punished and nonpunished conditions are presented for each group at the different dose levels in Fig. 1.

First, it should be noted that punishment resulted in the usual self-punitive phenomenon at each dose level $(.30$ dose, $F=34.09, \mathrm{df}=1 / 33$, $\mathrm{p}<.001 ; 1.20$ dose,$\quad F=17.18$ $\mathrm{df}=1 / 25, \quad \mathrm{p}<.001 ; \quad 5.82$ dose, $\mathrm{F}=15.86, \mathrm{df}=1 / 20, \mathrm{p}<.001)$. It may be seen that the effect of the drug, in general, was to suppress extinction performance (.30 dose, $\mathrm{F}=20.93, \mathrm{df}=1 / 33, \mathrm{p}<.001 ; 1.20$ dose, $F=15.79, \mathrm{df}=1 / 25, \mathrm{p}<.001$; 5.82 dose, $F=18.73, \quad \mathrm{df}=1 / 20$, $\mathrm{p}<.001)$. The interaction of Drug by Punishment was also significant at each dose level (.30 dose, $F=13.15$, $\mathrm{df}=1 / 33, \quad \mathrm{p}<.001 ; 1.20$ dose $\mathrm{F}=13.14, \mathrm{df}=1 / 25, \mathrm{p}<.001 ; 5.82$ dose, $F=10.62, \mathrm{df}=1 / 20, \mathrm{p}<.001$ ).

At the lowest dose, the nonpunished chlorpromazine group was not significantly lower than the nonpunished saline group.

DISCUSSION

Once again, punishment of an aversively motivated response during extinction produced self-punitive behavior. The results also showed that chlorpromazine was effective in stopping self-punitive behavior.

The assumption that chlorpromazine reduced fear, and thus reduced the strength of response, is supported by the data. The fear-reduction explanation, and thus the Mowrer-Brown one, is more strongly supported than a general activity-reduction hypothesis, since there was no significant difference between the nonpunished drug and saline-injected groups at the low dose level.

These effects, observed at the low-dose level, were interesting also because they showed that the self-punitive punishment procedure shows promise as a method for determination of the presence of a drug when other methods show no behavioral effects. These results suggest that the self-punitive paradigm might prove useful in drug-screening programs.

\section{REFERENCES}

BROWN, J. S. Factors influencing self-punitive locomotor behavior. In B. A. Campbell and R. M. Church (Eds.), Punishment and aversive behavior. New York: Appleton-Century-Crofts, 1969.

BROWN, J. S., MARTIN, R. C., \& MORROW, M. w. Self-punitive behavior in the rat: Facilitative effects of punishment upon resistance to extinction. Journal of Comparative \& Physiological Psychology, 1964, 5 . $127-133$.

ERVEY, D. E. The quality of motivation: Stopping self-punitive behavior by reducing emotionality. Presented at the Virginia Academy of Science, 1968 . Roanoke, Virginia.

MARTIN, R. C. One way to stop self-punitive behavior. Psychonomic Science, 1969, 14, 25-26.

MILLER, R. E., MURPHY, J. V., \& MIRSKY, A. I. The effect of chlorpromazine on fear-motivated behavior in rats. Journal of Pharmacological Experiments and Therapy, 1957, 120, 379-387. 